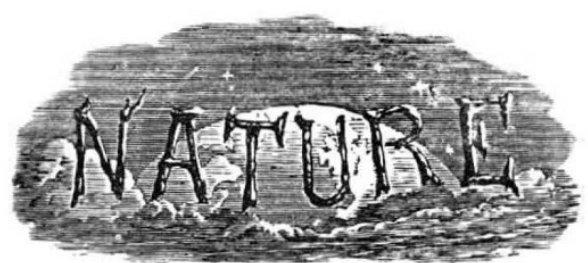

SATURDAY, JANUARY 27, I923.

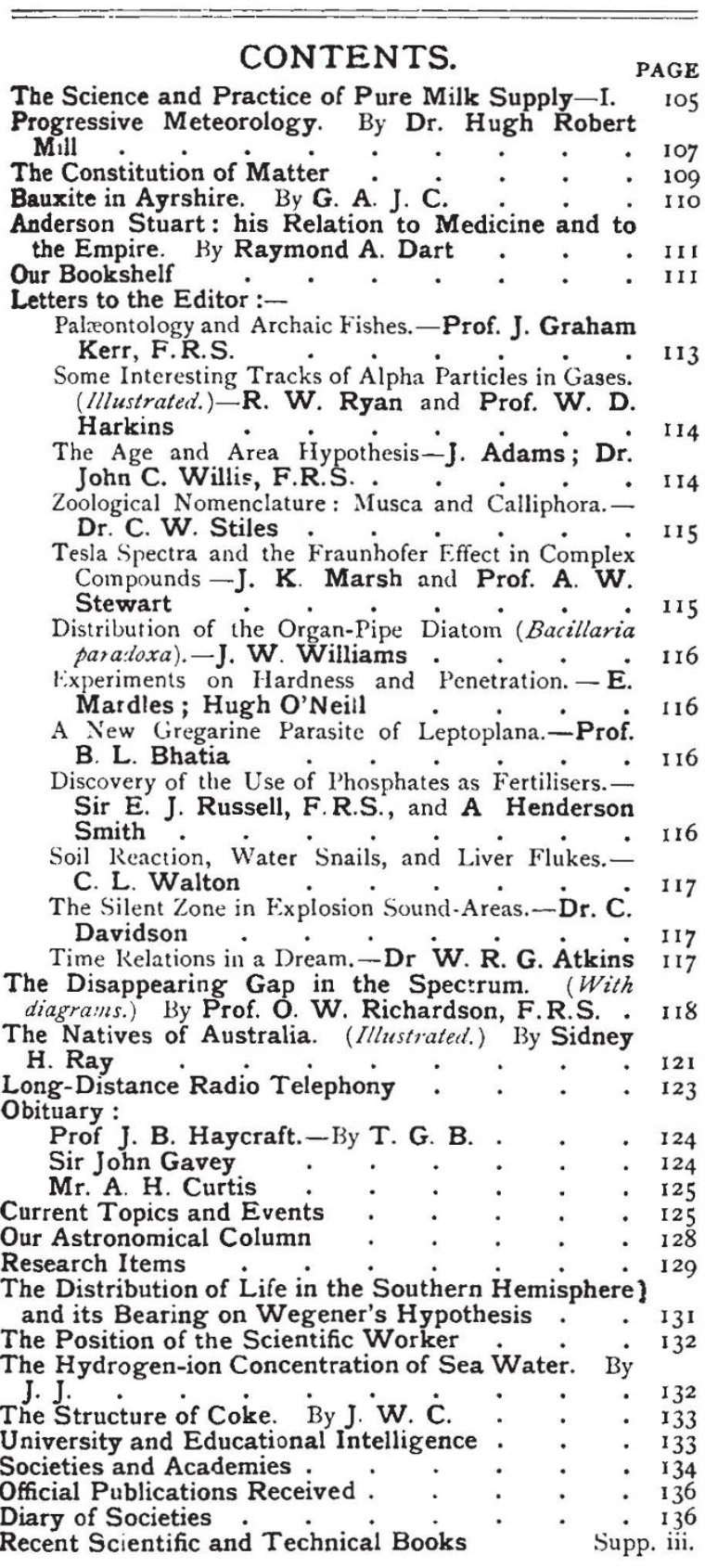

Editorial and Publishing Offices:

MACMILLAN \& CO., LTD.

ST. MARTIN'S STREET, LONDON, W.C. 2

\section{The Science and Practice of Pure Milk} Supply.

\section{I.}

THE history of our milk supply, especially when considered in relation to the corresponding history of the milk supply of the United States, illustrates more intimately, perhaps, than any other subject the necessity for the man of science to study the practical problems involved in the application of his discoveries, and for the administrator and the producer and trader to acquaint themselves with the added responsibilities and increased possibilities of improved trade bestowed by science.

We are chiefly concerned in NATURE with the scientific aspects of the milk problem; but at every stage these are interlocked with practical problems requiring the expenditure, or more correctly the investment, of much money to ensure the health of the community. A statement of some of the considerations involved will make these points clear.

The first point we make is frequently overlooked. An increase in the quantity of milk available for the general public, and particularly for children, is even more important than improved quality of the milk, though this also is a public health requirement of the first grade. In this country far too little milk is consumed. Biologists and chemists have demonstrated that no other food is so vital to the welfare and health of mankind as milk. McCollum, of Baltimore, has laid down the rule that every growing child should be allowed one quart of milk daily, and Lusk states that "no family of five should buy meat until they have bought at least three quarts of milk" daily. In Great Britain not half as much milk is consumed per head as in the United States, and it is to the lack of this element in the dietary of children that a large share of the common malnutrition and undergrowth, and the associated excessive proneness to disease is ascribable. There are abundant instances in which the daily giving of half a pint of milk to each child attending school in poor neighbourhoods has been followed by a marked raising of the general standard of health.

The above statement that an adequate quantity is even more important than an improved quality of milk, although it truthfully represents a neglected aspect of the milk problem, is obviously subject to the condition that milk of the present quality must be made safe either by pasteurisation on the large scale or by bringing it domestically near the boiling point.

Alongside of educational propaganda in favour of purer milk there is needed steady and persistent instruction through child welfare centres, in schools, and generally, to induce parents to spend on milk the greater part of

NO. 2778 , VOL. III] 
the money now devoted to beer. At the present time three times as much is spent by the British public on alcoholic drinks as on milk, and to this avoidable physiological impoverishment of the children, which is associated with the deficiency of milk, we can in large measure ascribe the proneness to catarrhs and the development of bronchitis, of rickets, and of tuberculosis.

Early, then, in any attempts at practical reform must be placed the need for educating the public into willingness to buy more milk-at least twice or three times as much as is now being bought, for daily dietetic use. It follows that any measures proposed for the purification of milk must be tempered by consideration of the degree of risk to health, the administrative practicability of the proposals, and the expenditure involved.

The necessity for milk sanitation, as for general sanitation, was first impressed on the public mind by the occurrence of epidemics attributed to contaminated milk. It was in 1857 that Dr. W. M. Taylor, of Penrith, traced an epidemic of typhoid fever to contaminated milk, and ten years later he traced an outbreak of scarlet fever to milk. In I $880 \mathrm{Mr}$. Ernest Hart collected accounts of fifty epidemics of typhoid, fifteen of scarlet fever, and four of diphtheria traced to infected milk supplies; and since then the number has become immensely greater, until, in recent years, commercial pasteurisation combined with a modicum of sanitary precautions on the farm and in the retailing of milk has been associated with a great decrease in the number of such outbreaks. In addition, septic sore throats have not infrequently been traced to milk derived from cows with udder inflammations; and, most important of all, a considerable proportion of human tuberculosis, especially in young children, has been attributed to milk.

The history of the relation of human to bovine tuberculosis is an interesting chapter in bacteriology. In 1896 Theobald Smith announced that the tubercle bacillus of cattle differed materially from that of human tuberculosis. In 1901 Koch made the sensational announcement in London that bovine tuberculosis did not infect human beings. Inasmuch as, prior to this statement, the stress of anti-tuberculosis agitation had been much more against bovine than against human sources of infection, Koch's dictum necessitated a re-investigation of the entire subject. A Royal Commission was appointed, and continued its inquiries for many years. The results of these and of many collateral investigations may be summed up in the statement that bovine tuberculosis undoubtedly does oecur in the human being, but that it is a minor cause of human tuberculosis. Furthermore, that, unlike infection of human origin, bovine infection can be effectively prevented-as can also the infection of such occasionally milk-borne diseases as scarlet fever, typhoid fever, and diphtheria,-by pasteurisation of milk, or by bringing milk domestically "just to the boil."

It was tuberculosis in the young subject which was regarded as chiefly caused by milk infection, but experimental observation of the type of bacillus found in children's tuberculous lesions has shown that less than one-third of tuberculosis in children under five years of age is of bovine origin, the greater part being derived from infection of human source. The abdominal tuberculosis and tuberculosis of joints and bones and of glands, which may be due to infection of bovine source, are often not fatal ; and it appears likely that, as Cobbett ${ }^{1}$ has estimated, the mortality caused by infection with the bovine type of tubercle bacillus at all ages is not more than six per cent. of that caused by bovine and human types of bacillus combined. This estimate was made sereral years ago. The proportion of human mortality from tuberculosis due to bovine infection is probably less now, for one of the striking features of tuberculosis mortality is its recent reduction at ages under five. Thus the deathrate from tuberculosis per million living at ages under five was 1213 in 1920 , as compared with an average rate of 1883 in I912-14. Inasmuch as only a relatively small proportion of this mortality in the earlier period was caused by infected milk, the main credit for the decline, after making any needed allowance for changes in medical certification, must be given to the diminution of human infection; and the entire result can reasonably be regarded as the joint product of measures for diminishing bovine tuberculosis, which, speaking nationally, have been on an extremely small scale, of measures for rendering bovine infection impotent (pasteurisation of milk and domestic heating), and of measures directed chiefly against human adult sources of infection. We have mentioned the six per cent. as a possible limit of the proportion of total tuberculosis mortality at all ages which is due to bovine infection, without intention to minimise its importance, for the annihilation of tuberculosis of bovine origin would greatly reduce the mass of human suffering, and this end is within reach by easily practicable measures, which would serve the interest of dairymen as much as that of the consumers of milk.

The possibility of acquiring tuberculosis or an acute infectious disease like scarlet fever, although the chief, are by no means the sole risks of contaminated milk. Past experience has shown an intimate-association between an impure milk supply and excessive infant mortality; and the remarkable reduction in

'L. Cobbett. "The Causes of Tuberculosis," Cambridge University Press, r917. 
infant mortality in the present century in this and in other countries has been associated with marked improvement in the cleanliness of milk, commercially and domestically. At each step scientific investigations have been important means to this end. The determination of the thermal death-point of pathogenic bacteria has shown the possibility of heating milk to a lower point than boiling, which, while removing the possibility of infection, leaves milk with its natural taste almost unimpared. The bacterial counting of milk, showing the close association between cleanly milking followed by immediate cooling of milk and a sparse bacterial count has given a great impetus to the supply of clean and cool milk, especially in America. The tuberculin test has been largely utilised as a means of discovering clinically undiagnosable tuberculosis in cattle, and of its elimination from herds. It is a condition of the official granting of a certificate of production of "Grade A (Tuberculin Tested)" Milk, in accordance with a recent Order of the Ministry of Health. The discovery in 1890 of Babcock's simple method of fat determination has had far-reaching consequences in securing high standards of food value in milk supplies, and in enabling the public when they desire to buy milk of known value. The list of items of indebtedness of the public and of milk purveyors to scientific laboratory workers might easily be extended.

In England there is a large excess of infant deaths in the three hottest months of the summer, and these are due in the main to diarrhœa. To discuss adequately the factors of heat, of impurity of food, of impurities apart from food (e.g. exceptionally in breast-fed babies) which are responsible for this devastating disease would require much space; but the following determined facts can be stated. Diarrhœa is rare in breast-fed infants; it is exceptional among the infants of the well-to-do, who can take adequate precautions in respect of food; but it is common in the infants of the poor, and has been found to be more common in infants fed on condensed milk than in infants fed on fresh cows' milk. This does not apply to dried or desiccated milk, infants consuming which appear to suffer much less from diarrhœa than infants artificially fed with other foods. The explanation of these facts is not far to seek. Domestic contaminations of milk are even more important than contaminations at the farm, in transport, or in the local shop, though these also are serious. Condensed milk is difficult to manipulate in a cleanly manner, dried milk is not so. Fresh milk can be more easily provided and, when domestically pasteurised, has been shown to be less liable to cause gastro-intestinal trouble in the summer months than diluted condensed milk. The details showing the need for aseptic precautions in milk preparation, all based on the science founded by Pasteur and applied by Lister, can easily be understood. In the last seventeen years active steps have been taken to instruct and guide mothers in the right feeding of their infants, and there can be little hesitation in ascribing the lowered infant mortality in large measure to this cause, and to the collateral general improvement in the milk as delivered at the home. This improvement has consisted largely in the increasing practice of commercial pasteurisation. Prior to 1900 the rate of infant mortality averaged 140 to 160 ; in the last quinquennium it was only 85 per rooo births.

The above consideration of evils and of possible channels of improvements naturally leads to a consideration of the administrative aspect of the problem. This in the main consists in the application of scientific methods to the milk industry, which will be discussed in our next issue.

\section{Progressive Meteorology.}

Board of Education. Catalogue of the Collections in the Science Museum, South Kensington, with Descriptive and Historical Notes and Illustrations: Meteorology. Pp. ro7 +6 plates. (London: H.M. Stationery Office, r922.) Is. $6 d$. net.

Air Ministry: Meteorological Office, London. A Short Course in Elementary Meteorology. By W. H. Pick. (M.O. 247.) Pp. II8. Is. 6d. net. The Observer's Handbook. Approved for the use of meteorological observers by the Meteorological Office, and the Royal Meteorological Society. r92 I edition. (M.O. г9г.) Pp. $\mathrm{xxx}+\mathrm{I} 40+\mathrm{I} 8$ plates $+\mathrm{I} 0+\mathrm{I} 7$ plates $+5.75 .6 \mathrm{~d}$. net. Cloud Forms according to the International Classification: The Definitions and Descriptions approved by the International Meteorological Committee in 19ro. With an atlas of photographs of Clouds selected from the Collection of Mr. G. A. Clarke of the Observatory, Aberdeen. (M.O. 233, and edition.) Pp. ro + I7 plates + 5. Is. 6 d. net. . Notes on Meteorological Corrections for the use of Gunners. By D. Brunt and J. Durward. Pp. x8. 3d. net. Forecast Code for the Abbreviation of Weather Forecasts transmitted by Telegraphy or Radiography. Pp. I8. Is. net. The New International Code for Meteorological Messages, 1922. Pp. 20. 4d. net. Weather Forecasting in the North Atlantic and Home Waters for Seamen. By Com. L. A. Brooke-Smith. Pp. 24. 6d. net. The Wireless Weather Manual. Pp. 24. 9d. net. (London: H.M. Stationery Office, r92I-I922.)

C $\mathrm{N}$ turning over this packet of the latest official publications on meteorology I feel disposed to survey them in a contemplative rather than in a critical 